\title{
INFORMAÇÃO, CONHECIMENTO E VALOR DA INFORMAÇÃO
}

\author{
INFORMATION, KNOWLEDGE AND INFORMATION \\ VALUE
}

Juliana Cardoso dos Santosa

Marta Lígia Pomim Valentimb

\begin{abstract}
RESUMO
Introdução: A informação e o conhecimento em ambientes organizacionais constituemse em recursos imprescindíveis que tem valor estratégico e possuem inter-relação com a produtividade e competitividade organizacional. Objetivo: Evidenciar por meio da literatura, a importância da informação e do conhecimento para a atribuição de valor ao negócio organizacional. Metodologia: No que tange aos procedimentos metodológicos, esse ensaio teórico é de natureza qualitativa, tipologicamente descritivo e exploratório, objetivando evidenciar por meio da literatura, a importância da informação e do conhecimento para a geração de valor ao negócio da organização. Resultados: Como resultados, identificou-se que, ainda, não há consenso na área de Ciência da Informação - e não é necessário que haja, sobre o valor da informação como negócio. Conclusões: Considera-se que os achados desta pesquisa contribuam para enriquecer o referencial teórico do campo científico da Ciência da Informação, tendo em vista que é uma temática que se constitui em uma tendência, mas também uma necessidade nos estudos organizacionais.
\end{abstract}

Descritores: Informação. Conhecimento. Valor da Informação.

\section{INTRODUÇÃO}

O segmento industrial necessita do acesso à informação de modo rápido e eficaz para desempenhar suas atividades voltadas ao negócio. Dessa maneira, é possível afirmar que a informação e o conhecimento voltados ao negócio estão diretamente relacionados ao modo de pensar e produzir um novo produto,

\footnotetext{
a Doutora e Mestre em Ciência da Informação pelo Programa de Pós-Graduação em Ciência da Informação Universidade Estadual Paulista (PPGCI/UNESP - Marília). Docente do Departamento de Ciência da Informação da Universidade Estadual de Londrina (UEL). E-mail: julimath21@gmail.com

b Doutora em Ciências da Comunicação pelo Programa de Pós-graduação em Ciências da Comunicação da Universidade de São Paulo (PPGCOM/USP). Docente da Universidade Estadual Paulista (UNESP). E-mail: valentim@valentim.pro.br
} 
melhorar um processo industrial ou prestar um serviço ao cliente. Nessa perspectiva, ambos os elementos atuam em diferentes contextos, possibilitando a melhoria da qualidade e da produtividade de processos e fluxos, ou seja, são insumos para o desenvolvimento organizacional.

Destaca-se que ao abordar as temáticas informação, conhecimento e valor da informação no ambiente organizacional é necessário considerar a organização em sua totalidade - seu capital intelectual abrangendo colaboradores, clientes, concorrentes e fornecedores, pois defende-se que as informações internas e externas são necessárias para manter o equilíbrio organizacional, sendo que o uso de informação no ambiente organizacional está relacionado a aspectos culturais e não é uma atividade puramente racional.

Segundo Valentim (2008) só quando o indivíduo compreende o significado da informação, está pode realmente ser nomeada de 'informação', quando não há compreensão por parte do sujeito esta não se configura como informação. Nesse contexto, o valor atribuído a informação é dado pelo sujeito organizacional e só tem realmente significado quando se transforma em processos, produtos e serviços.

Sabe-se que a informação e o conhecimento do e no ambiente organizacional tem caráter construtivo e subjetivo uma vez que os indivíduos só conseguem significar, por meio de relações e contextos vivenciados e compreendidos, visto que qualquer fazer é permeado por lembranças (informação com significado) e esquecimentos (não há compreensão/apreensão).

Segundo Valentim (2008) a informação pode ser considerada objeto ou fenômeno. Objeto, pois pode ser materializada por meio de um suporte, sendo que as informações e conhecimentos ali explicitados podem ser socializados; fenômeno, pois o sujeito irá usar diferentes cognições para formalizar a informação e construir conhecimento. Destaca, ainda, que nos ambientes organizacionais a informação e o conhecimento são diferenciais competitivos, visto que "[...] todas as atividades desenvolvidas desde o planejamento até a execução das ações planejadas, assim como o processo decisório, são apoiadas por dado, informação e conhecimento" (VALENTIM, 2006, p. 9). 
As informações de planejamento e execução que reduzem ambiguidades se constituem em insumo para a construção de conhecimento, indispensável a sobrevivência organizacional. Sendo assim, é possível inferir que a informação é elemento com significado que transforma a sociedade, social e economicamente, e seu conceito está inter-relacionado ao uso, já o conhecimento estabelece correlações ligadas a questões cognitivas e de comunicação (CHOO, 2003).

A informação tem valor estratégico e melhora processos, produtos e serviços organizacionais, uma vez que é ferramenta para a obtenção de competitividade. Contudo, sabe-se que a mesma informação terá significado diferente para indivíduos distintos, pois depende do contexto em que ela foi criada e das cognições estabelecidas para sua apropriação, uso e reuso (ILHARCO, 2003; TARAPANOFF, 2006).

A informação e o conhecimento estruturados potencializam seu uso como um diferencial estratégico e como negócio/commodity, visto que a mesma informação pode ser interpretada por diferentes indivíduos e em situações diversas, a construção de novos conhecimentos alicerçados em erros e acertos já experienciados que potencializam a tomada de decisão assertiva no ambiente organizacional.

Compreende-se que há convergências entre os conceitos de informação e conhecimento e, assim, no intuito de não causar incoerências, primeiramente são apresentados, de acordo com a literatura da Ciência da Informação $(\mathrm{Cl})$ e áreas afins, alguns conceitos de informação e conhecimento que culminam nas discussões sobre o valor da informação que circundam as propostas deste ensaio teórico que configura-se como descritivo exploratório (TRIVIÑOS, 1990).

Segundo Triviños (1990) e Severino (2007) estudos descritivos exploratórios visam aprofundar o conhecimento sobre determinada realidade, portanto, objetivou-se desenvolver uma revisão bibliográfica sobre as temáticas que sustentam a discussão aqui proposta, no intuito de aprofundar o debate sobre o tema. Nesse contexto, o objetivo deste ensaio teórico é evidenciar por meio da literatura, a importância da informação e do conhecimento para a atribuição de valor ao negócio organizacional. Justifica-se a relevância deste 
debate, uma vez que o indivíduo lida com informação e conhecimento todo o tempo, entretanto, vale esclarecer conceitualmente ambos os termos, pois as semelhanças podem causar incoerências, principalmente em ambientes dinâmicos e competitivos, sendo necessário o discernimento sobre sua interdependência, ou seja, a informação e o conhecimento estão relacionados entre si por uma recíproca dependência e são fundamentais para que tenham seu valor reconhecido em ambientes competitivos.

O texto está estruturado em quatro seções em que se apresenta as considerações iniciais do estudo e os procedimentos metodológicos e, posteriormente, aborda-se as temáticas: 'Informação e Conhecimento', o 'Valor da Informação como Negócio' e as 'Considerações Finais'. Destaca-se que esse ensaio não finda os esforços em compreender as questões abordadas, mas sim realiza diálogos com base na literatura consultada almejando apresentar reflexões, visando uma melhor compreensão do objeto e fenômenos investigados.

\section{INFORMAÇÃO E CONHECIMENTO}

Ao debater sobre os elementos informação e conhecimento no âmbito da $\mathrm{Cl}$, observa-se que um dos conceitos mais usados para defini-los perpassa por três aspectos: a) informação-como-coisa - explícita, formal, sistemática e codificada; b) informação-como-conhecimento - tácita, pessoal, composta de habilidades técnicas, know-how; cognitiva, modelos mentais e crenças; c) informação-como-processo - pressupõe intercâmbio, uso, modifica estruturas, voltada a ação (BUCKLAND, 1991, tradução nossa).

Buckland (1991) infere, ainda, que o termo informação é um componente intrínseco a todos os processos organizacionais, pois para ser "coisa" deve estar explicitada, formalizada, sistematizada e codificada, pois rege processos burocráticos que precisam de prova documental, para que alicercem processos formais inerentes ao ambiente organizacional. Também pode ser "conhecimento", pois toda organização é composta por capital intelectual, sujeitos organizacionais que possuem individualidades, conhecimentos, competências e habilidades que possibilitam o know-how (saber como) e o know- 
why (saber porque), e isso é estabelecido por meio de processos cognitivos, modelos mentais e crenças pessoais e organizacionais. Além disso, também é "processo", pois é por meio dele que a informação é socializada, seu uso é fomentado e, assim, tem potencial para modificar estruturas com foco na ação, possui valor, pois como coisa, conhecimento e processo, circunda todo o ambiente da organização potencializando ações inovadoras e a competitividade organizacional.

Para Braman (1989, tradução nossa) a informação se divide em quatro categorias 1) informação como recurso - sujeitos isolados, informação fragmentada, sem vínculos e fluxos, ausência de poder; 2) informação como mercadoria - cadeia de produção, valor e poder econômico, intercâmbio e uso; 3) informação como percepção de padrão - adição de contexto, passado e futuro afetados e com efeitos; estrutura social e articulação, poder próprio com efeitos isolados; 4) informação como força constitutiva na sociedade dimensionamento de contexto, é afetada pela estrutura social, articulação, complexidade, poder de construção, realidade social e física.

Nessa perspectiva, no âmbito das organizações a informação como negócio tem valor no momento que é suporte para ampliar a competitividade, ou seja se relaciona à informação como mercadoria, está vinculada a cadeia de produção, ou seja, etapas consecutivas em que o insumo, neste caso a informação, sofre uma sequência de modificações até constituir-se em um produto final (bem ou serviço), que passou por processos de produção, processamento, armazenamento, distribuição e comercialização, sempre interrelacionados ao indivíduo.

A informação objeto ou fenômeno (VALENTIM, 2008) pode se constituir em mercadoria e possuir valor econômico, bem como pode gerar valor agregado adquirido durante o processo de transformação. O valor econômico pode ser mensurável ou não, pode estar relacionado ou não a valor financeiro, social ou cultural que, por sua vez, possibilita troca, uso e reuso, proporcionando mais poder aos que a detém.

A informação pode reduzir ou aumentar incertezas, por consequência possibilitam a geração de diferenciais competitivos e, exatamente por essa 
razão, é preciso gerenciá-la da mesma maneira que se gerencia os recursos humanos e materiais (CIANCONI, 1999).

A informação pode se expandir, ser completada, substituída, transformada, disseminada e compartilhada. Ela pode ser considerada um produto, negócio ou mercadoria, porquanto ela impulsiona o desenvolvimento da sociedade, e o mercado exige, cada vez mais, que as organizações empresariais sejam capazes de produzir bens e serviços baseados em informação (TARAPANOFF; ARAÚJO JR.; CORMIER, 2000).

Pode-se afirmar que inovar é buscar o novo e a informação é subsídio para que isso ocorra A informação é insumo que permeia as ações da organização, possibilitando por meio de análise de possíveis perspectivas, a previsão de tendências e se constituindo em suporte essencial para a tomada de decisão.

Para Valentim (1994) a informação pode ser classificada em estruturadas - já sofreram organização e tratamento, estão acessíveis; estruturáveis disponível internamente a organização, mas não organizadas e tratadas, não podem ser acessadas; não estruturadas - disponíveis externamente a organização de difícil acesso e recuperação. Sendo assim, lidar com informações estruturadas, estruturáveis e não estruturadas de maneira sinérgica potencializam a competitividade, visto que é a partir da capacidade de explorar uma oportunidade ou reduzir uma ameaça que a organização pode atribuir valor a informação em um determinado contexto situacional.

Corrobora-se com a ideia de Almeida Júnior (2015) que a informação não é transferida, mas sim apropriada pelo indivíduo, uma vez que cada informação só existe e só se constitui em uma informação para a pessoa que a está usando, no momento em que ocorre a mediação/relação.

Infere-se que a informação também é um processo que modifica estruturas, que pode ser assimilada e internalizada e é imprescindível para o desenvolvimento das organizações, pois o indivíduo precisa ter consciência acerca do que sabe (MORIN, 1999)

É importante destacar que "[...] a informação pode ter significados diferentes e gerar possibilidades diversas em diferentes indivíduos e em 
diferentes situações" (ILHARCO, 2003, p. 38). São esses diferentes significados e possibilidades que potencializam o valor da informação para as organizações competitivas.

A informação é complexa e no ambiente organizacional pode ter várias aplicabilidades e denominações, como apresenta Valentim (2006): informação estratégica; informação voltada ao negócio; informação financeira; informação comercial; informação sobre gestão, informação tecnológica; entre outras, que podem estar apresentadas de maneira estruturada, estruturável ou não estruturada, mas que fazem parte dos processos organizacionais e, portanto, contribuem para seu desenvolvimento, desde que geridas de modo eficiente. Discute-se a respeito da informação como negócio/commodity, uma vez que ela potencializa a competitividade de organizações empresariais por ser suporte à tomada de decisão.

Trabalhar com informação tanto formal quanto informal é fundamental, e quanto mais bem gerenciada, organizada e disseminada no ambiente organizacional, mais rapidamente ela poderá contribuir estrategicamente e gerar produtos competitivos. Sendo assim, compreender a informação, o conhecimento e o valor da informação como negócio como elementos básicos da competitividade organizacional oportuniza o avanço empresarial que é fundamental para atuar em mercados competitivos.

Para Besson e Possin (1996, p. 35) "[...] a informação, seja qual for a sua natureza, divide-se em quatro elementos exclusivos de quaisquer outros, sendo aberta, ou fechada, e oral, ou escrita". Nessa divisão "[...] aberta, ou fechada, e oral, ou escrita" a informação deve ser compreendida como um objeto de atenção pelo setor industrial, ou seja, a informação e o conhecimento devem ser considerados um ativo, um negócio, uma commodity.

A informação e o conhecimento são criações humanas e, por essa razão, nem sempre é fácil gerenciá-los, pois para tanto é essencial compreender o fator principal vinculado a ambos os elementos: as pessoas, isto é, os sujeitos organizacionais geradores e usuários de informações e conhecimentos.

A informação é um componente intrínseco das organizações empresariais, pois se constitui no conhecimento registrado, comunicado e 
passível de socialização, no qual diferentes autores atribuem significados distintos à ela, ou seja, seu conceito não apresenta consenso quanto ao seu significado, visto que é definida de acordo com o contexto e finalidade no qual está sendo empregada.

No intuito de esclarecer e demonstrar essa relação de interdependência entre informação e conhecimento, apresentar-se-á algumas definições sobre 'conhecimento'.

O conhecimento advém de processos cognitivos realizados pelo ser humano e, de acordo com a literatura, pode ser dividido em tácito e explícito. $O$ conhecimento tácito é aquele que pertence somente ao indivíduo, por outro lado o conhecimento explícito é codificado na forma de símbolos passíveis de serem interpretados, porém os dois são indissociáveis, pois ao explicitar o conhecimento tácito, este gera novo conhecimento tácito.

Para Choo (2003, p. 37)

Conhecimento tácito é conhecimento pessoal, que é difícil formalizar e comunicar a outros. É constituído de know-how subjetivo, dos insights e intuições que uma pessoa tem depois de estar imersa numa atividade por um longo período de tempo. Conhecimento explícito é o conhecimento formal, que é fácil transmitir entre indivíduos e grupos. É frequentemente codificado em fórmulas matemáticas, regras, especificações, e assim por diante.

O conhecimento se relaciona sinergicamente entre o tácito e o explícito, e no ambiente organizacional os sujeitos desse processo precisam perceber que a informação é matéria prima e insumo para a construção de conhecimento.

Segundo Valentim e Gelinsk (2005) o conhecimento é único, pois depende de um sujeito cognoscente e de suas estruturas cognitivas para ser gerado. Um fator predominante nesse processo de construir novos conhecimentos é a socialização, pois propicia que este saiba o que conhece e, assim, possa construir 'novo' conhecimento.

O conhecimento é reutilizável e seu valor é determinado pelo sujeito conforme sua necessidade e uso/aplicação, pressupondo apropriação e explicitação para que seja útil e favoreça a inovação e a competitividade organizacional.

O conhecimento para Morin (1999, p. 18) “[...] é um fenômeno 
multidimensional, de maneira inseparável, simultaneamente físico, biológico, cerebral, mental, psicológico, cultural, social [...]", sendo um elemento cognitivo intrínseco ao homem. Todas as facetas apresentadas por Morin expressam a complexidade do conhecimento, visto que o mesmo deve ser considerado sob vários pontos de vista, sendo um fenômeno que não se dissocia e ocorre independente da relação com outras coisas ou fatos.

O conhecimento é uma mistura espontânea de experiências, valores, contexto e insight vivenciados, que proporciona avaliar e incorporar novas experiências e que constrói a memória, pois tem origem e aplica-se a quem o conhece. É uma abstração interior, de algo experimentado pelo indivíduo e de difícil explicitação (DAVENPORT; PRUSAK, 1998a; SETZER, 1999).

Para Setzer (1999) a informação se associa a semântica e o conhecimento se associa a pragmática. A semântica estuda o significado e a interpretação desse mesmo significado, já a pragmática estuda o contexto de uso.

O conhecimento não é estático e se modifica influenciado e influenciando o ambiente, e requer uma vivência do objeto do conhecimento. Segundo Nonaka e Takeuchi (1997) o conhecimento é processual e nas organizações seu foco deve se voltar à socialização e à partilha de experiências, para que seja incorporado e se torne parte do ambiente. Os mesmos autores propõem um modelo de criação do conhecimento dividido em cinco fases: (1) compartilhar o conhecimento tático; (2) criar conceitos; (3) justificar conceitos; (4) construir um arquétipo; (5) disseminar o conhecimento.

$\mathrm{Na}$ primeira fase de compartilhamento diversos sujeitos partilham habilidades e experiências, trabalhando em equipe e desenvolvendo modelos mentais, ou seja, socializam seu conhecimento tácito. Na segunda fase de criação de conceitos, o diálogo favorece a socialização, pois tentam traduzir/explicitar os modelos mentais construídos, isto é, exteriorizam o conhecimento. Na terceira fase relacionada a justificar os conceitos, é possível verificar se os conceitos criados estão alinhados aos objetivos e estratégias organizacionais e se satisfazem as necessidades do todo organizacional. $\mathrm{Na}$ quarta fase de construir um arquétipo, se materializa o conceito, é o modelo ou 
a inovação, é a junção do que foi recentemente construído e o que já se possuía. A quinta e última fase se constitui na disseminação do conhecimento, que ativa novos ciclos de criação de novos conhecimentos.

Para Wikstrom e Normann (apud CHOO, 2003, p. 212) o conhecimento se distingue em três tipos de processos do conhecimento nas organizações: (1) processos gerativos - criado durante a solução de problemas, aumentando os recursos e capacitando para a criação de novos conhecimentos; (2) processos produtivos - reproduz, pois acumula e reproduz o conhecimento gerado; (3) processos representativos - transmite conhecimento gerando valor, é o conhecimento manifesto - know-how.

A competência ou know-how propiciam valor ao conhecimento que a organização gera e este processo é colaborativo, pois a informação e o conhecimento são potencialmente competitivos se estruturados e socializados em ambientes não ambíguos atribuindo valor a informação como negócio. $A$ informação e o conhecimento podem ser reconhecidos como insumos, dessa maneira, têm valor e geram o conhecimento que se constrói pela socialização e apropriação de novos conhecimentos. A socialização de informações e conhecimentos podem contribuir com o ambiente competitivo das organizações empresariais, pois propiciam soluções inovativas.

Nonaka e Takeuchi (1997) apresentam a 'Espiral do Conhecimento' com algumas indicações desse processo de criação de conhecimento.

Figura 1 - Espiral do Conhecimento.

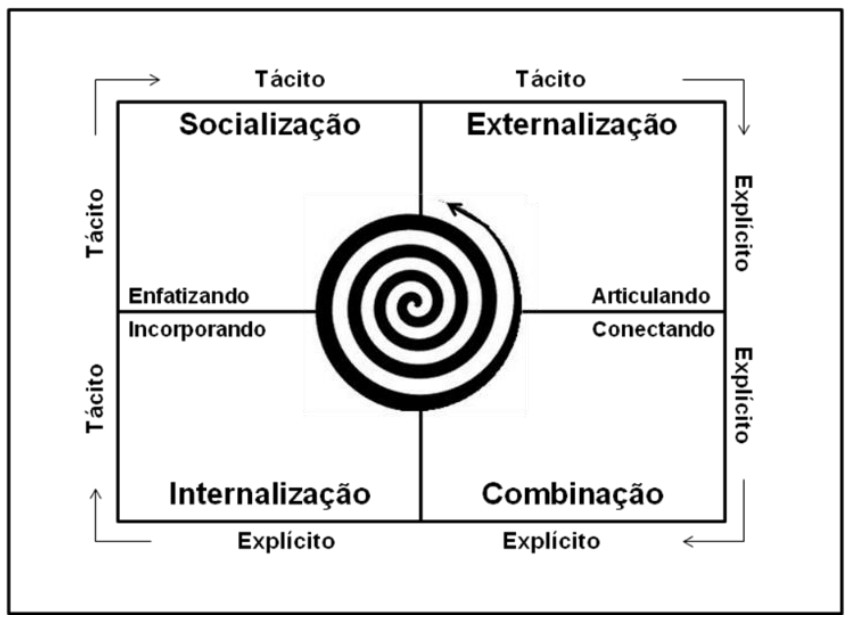

Fonte: Nonaka e Takeuchi (1997).

Por meio da Espiral do Conhecimento os autores Nonaka e Takeuchi 
(1997) destacam a dinâmica do conhecimento entre o tácito e o explícito. O conhecimento tácito se divide em duas dimensões, sendo: a primeira técnica know-how, e a segunda cognitiva, modelos mentais, cultura que reflete a dimensão humana do conhecimento tácito. Por outro lado, o conhecimento explícito é o conhecimento externalizado que pode ser registrado em distintos suportes.

Por meio da Espiral os autores supracitados apresentam quatro modos de transformação do conhecimento encarregados pela aprendizagem e inovação dos sujeitos organizacionais, a saber: socialização, internalização, externalização e combinação. A conversão do conhecimento se refere a um ciclo contínuo de interação entre os conhecimentos tácitos e explícitos, com a participação ativa do sujeito cognoscente. Esse processo foi nomeado de 'Processo SECl' [acrônimo das palavras socialização, externalização, combinação e internalização], cujas fases de conversão são:

a) Socialização: converte o conhecimento tácito em conhecimento tácito, a socialização possibilita que o processo pelo qual se adquire conhecimento tácito, seja realizado por meio do compartilhamento de experiências;

b) Exteriorização: converte o conhecimento tácito em conhecimento explícito, cujo processo traduz o conhecimento tácito em conceitos explícitos, por meio da utilização de metáforas, analogias e modelos;

c) Combinação: converte conhecimento explícito em conhecimento explícito, cujo processo reúne conhecimentos explícitos provenientes de várias fontes de informação;

d) Internalização: converte conhecimento explícito em conhecimento tácito, cujas experiências adquiridas em outros modos de construção de conhecimento são internalizadas pelos indivíduos, consolidando os modelos mentais ou rotinas de trabalho comuns (NONAKA; TAKEUCHI, 1997).

Assim, a socialização se refere a troca de conhecimentos tácitos que ocorre entre os indivíduos/compartilhamento de experiências e vivências; a externalização se relaciona a conversão de conhecimentos tácitos em signos e 
símbolos, ou seja, em conhecimento explícito; a combinação se refere ao agrupamento de conhecimentos explícitos; e a internalização se relaciona à conversão do conhecimento explícito em tácito, resultante de interpretações do sujeito cognoscente.

Os processos se assemelham a espiral pois são cíclicos, ou seja, por meio da socialização o conhecimento tácito é substituído e na sequência convertido em explícito por meio da externalização. Na combinação o conhecimento se associa ao que já existe, gerando novos conhecimentos e, finalmente, é internalizado e se explicita por meio de manuais e normas, fazendo com que o processo se reinicie por meio da socialização, afinal a criação do conhecimento é um processo dinâmico e contínuo.

Kirk (1999) afirma que o conhecimento novo sempre começa com um indivíduo e é o conhecimento pessoal desse indivíduo que se transforma em conhecimento organizacional que é de valor para a organização.

Percebe-se que 0 entrelaçamento conceitual entre informação e conhecimento é inevitável, pois a informação é insumo do conhecimento, visto que sem informação o conhecimento não é possível, assim quando a informação atinge os sujeitos organizacionais, deixa de ser informação e se transforma em conhecimento.

Rezende, Pereira e Oliveira (2016, p. 78) enfatizam que a existência de ambientes e artefatos são capazes de mobilizar os sujeitos organizacionais de maneira que esses ativem seus excedentes cognitivos "[...] soma de tempo, energia e talento livres que usados de maneira colaborativa, permitem que indivíduos isolados se unam e reúnam para grandes realizações [...]" e proporcionem diferenciais para as organizações.

Transmitir informação e conhecimento com qualidade no ambiente organizacional aumenta o valor de tais ativos, pois geram novas informações e conhecimentos, quanto mais consumimos mais produzimos.

\section{VALOR DA INFORMAÇÃO COMO NEGÓCIO}

No intuito de apresentar as semelhanças e de não causar incoerências a seção anterior evidenciou que a informação e o conhecimento são insumos 
capazes de influenciar e modificar contextos, elementos estes que se caracterizam como potencialmente competitivos, porquanto têm o poder de gerar progresso econômico, tecnológico, industrial, isto é, as organizações têm na informação e nos recursos informacionais um forte instrumento de trabalho, uma vez que estes subsidiam os processos, atividades e tarefas valorando a informação como negócio no contexto organizacional.

Acredita-se que o valor da informação como negócio reside no benefício de minimizar incertezas, a partir da aprendizagem com os erros e os acertos, reduzir incertezas durante o processo decisório, visto que informação e conhecimento são fatores estratégicos para 0 ambiente organizacional $e$ compõem o seu ativo que, por sua vez, busca constantemente ampliar seu potencial inovativo e competitivo.

Herscovici (2014) e Marx (1984) destacam a metamorfose do valor, a partir do surgimento do trabalhador intelectual coletivo, na qual a produção de riqueza se manifesta na forma de capital intangível, por sua natureza imaterial. O valor da socialização crescente, da heterogeneidade e da valoração das especificidades, evidenciando a necessidade de reavaliar o valor de diferentes paradigmas econômicos. $\mathrm{Na}$ informação como negócio existe necessariamente o valor de troca e de uso da informação, visto que é somente no contexto de troca que surge o valor de uso e as questões de valor tem sempre caráter social e contextual, logo perpassam o ambiente organizacional.

A dificuldade de se considerar o valor da informação está relacionada ao fato de não se considerar todos os recursos materiais e humanos envolvidos na sua produção, visto que informação só é considerada informação quando possui significado e é compreensível.

Segundo Almeida e Varvakis (2005, p. 55) "[...] o valor da informação dependerá de um contexto ou situação que lhe atribuirá este valor, e será um sujeito que, além de fazer uso, dará significado ao conteúdo veiculado [...]", no caso da tomada de decisão em organizações empresariais que tem como base a informação e o conhecimento para reduzir ambiguidades, e usam erros e acertos como suporte informacional, o sujeito constrói conhecimento por meio de seu know-how e faz uso atribuindo significado a informação, e esta tem valor 
para o negócio podendo ser considerada mercadoria, pois usando o repertório e o repositório organizacional, estes podem subsidiar a diversas soluções inovativas.

Segundo os autores supracitados "[...] o valor da informação propriamente dito é a validade e a relevância que a informação representa a um determinado indivíduo (ou grupo)" (ALMEIDA; VARVAKIS, 2005, p. 55). Sendo assim, a informação sempre tem valor potencial, porém seu valor depende de subjetividades inter-relacionadas a um sujeito em determinado grupo e contexto.

Reduzir incertezas se relaciona diretamente a custo, tempo e contexto, logo o processo tem valor transformando a economia global, gerando vantagem competitiva, por meio da redução dessas incertezas (CASTELLS, 2001).Nesse contexto, a valoração da informação como negócio é imprescindível, pois é possível inferir que toda informação passível de gerar lucro pode tornar-se um bem, entretanto, é sabido que ambiguidades e desconfortos relacionados ao valor da informação existem, e a centralidade da informação nos processos contemporâneos exigem o enfrentamento desse desconforto (LOPES, 2008).

Organizações empresariais se alicerçam constantemente em informação e conhecimento para atingir metas e se sobrepor no mercado em que atuam. Em vista disso, é necessário compreender a informação e o conhecimento como diferenciais competitivos, uma vez que na sociedade contemporânea o modelo econômico voltado a competitividade é real, além disso tem causado significativas mudanças na estrutura das organizações, visando a tomada de decisão rápida e eficaz.

Segundo Capurro (2003) o valor da informação faz com que reducionismos nas práticas dos profissionais da informação sejam questionados, pois o fazer de tais profissionais abrange muitos problemas.

O valor da informação, sua mais-valia com respeito ao mero conhecimento, consiste precisamente da possibilidade prática de aplicar um conhecimento a uma demanda concreta. Assim considerado, o conhecimento é informação potencial. Não é difícil ver aqui a relação entre nossa disciplina e o trabalho sempre difícil e arriscado de interpretar, sobretudo se esse trabalho não se reduz a decifrar um texto obscuro, mas, sim, abrange todos os problemas reais e não menos obscuros e "anômalos" do existir humano (CAPURRO, 2003, não paginado).

Aplicar conhecimento a uma demanda concreta é evidenciar o potencial 
da informação, tomar decisão com base na informação. No entanto, só é possível debater a respeito do valor da informação como mercadoria se o escopo científico for ampliado. Segundo Santos et al. (2017, p. 569):

Valorar a informação não é tarefa fácil, e nem é consenso que a informação possua um valor monetário, pois ela é um bem intangível. No entanto entender que dentro do ambiente organizacional a informação é fundamental e imprescindível para tomada de decisão eficiente [é fundamental].

Segundo Clemente e Souza (2004, p. 72) um fator determinante e que dificulta a valoração da informação é o "[...] fato de ser muito generalizada a prática de troca de informação, não havendo propriamente um preço para o produto oferecido. [...], o que pode ser uma tarefa sujeita a premissas e estimativas discutíveis".

Cabe as organizações usarem características como: confiabilidade, relevância, clareza e velocidade em benefício próprio, potencializando seus diferenciais. Lopes (2008, p. 78) afirma que o reconhecimento do valor econômico da informação, regula a coordenação e equilíbrio deste mesmo sistema econômico, visto que "[...] a informação é um bem cujo valor consiste nas 'comunicações a respeito de fatos acontecidos no mercado ou na sociedade, que possam influenciar os negócios ou as condutas sociais [...]"' (LOPES, 2008, p. 78).

Essas comunicações ocorrem interna e externamente ao ambiente organizacional, sendo fundamental o monitoramento de clientes (internos e externos), concorrentes e fornecedores que influenciam e são influenciados.

A informação tem o potencial para preencher espaços, segundo Sheth, Mittal e Newman (2001) o valor só é criado se satisfaz necessidades, e como as necessidades não são as mesmas para todos os indivíduos ou organizações, podem atender melhor uma demanda do que outra, sendo influenciados pelo contexto, podendo ser universal, pessoal ou ambos.

A informação como negócio pode se modificar, aumentando ou diminuindo seu valor de acordo com o tempo, contexto, uso e/ou aplicação. Pode impulsionar substancialmente o negócio organizacional, haja vista que seu valor está diretamente inter-relacionado ao repertório organizacional, ou seja, ao contexto que a organização foi capaz de reter e a cultura que ela desenvolveu 
ao longo de sua história (SANTOS, 2019).

Segundo Lopes (2008) a informação possui dupla natureza: pode ser classificada como: a) bem público - disponível a toda coletividade e b) bem privado - trocada no mercado e parcialmente disponível, evidenciando sua incompletude.

As informações competitivas em sua maioria estão disponíveis publicamente, cabendo a organização localizá-las e gerenciá-las em benefício próprio, transformando-as em ativo organizacional que pode ser trocado no mercado, que possui valor e está intrinsicamente ligada a esfera da produção, vista como insumo a ser transferido ou como resultado/produto, tangível ou intangível.

Complementando a ideia de que o valor da informação está relacionado a produção, Bolaño (2000) classifica o conceito de informação na esfera produtiva da seguinte maneira: informação unidirecional - acumulação de capital, hierarquizada, objetiva e direta, não mediada e a informação horizontal - cooperativa e a serviço na valorização do capital, processo de apropriação pelos sujeitos e reprocessamento. Segundo Lopes (2008, p. 82)

A informação reside, portanto, na interação entre um sujeito e um objeto, ou sujeito a sujeito, não sendo nem atributo do objeto, nem do sujeito do agente, mas 'sempre uma relação entre ambos'. É, portanto, atividade de trabalho vivo. Dessa forma, a informação incorporada nos mais diversos suportes, só terá valor se percebida e atualizada pelo trabalho vivo durante seu processo de trabalho, removendo as incertezas e aleatoriedades do sistema e, com isso, otimizando sua performance.

Ainda, segundo Lopes (2008, p. 83), "[...] o valor da informação reside justamente no tempo poupado e não mais, como no conceito clássico de maisvalia, no tempo agregado.

Ao tratar a informação como negócio, deve-se ter clareza que a troca é quem cria demanda. Para Moresi (2000) a informação e o conhecimento por serem bens abstratos e intangíveis, seu valor está sempre associado a um, "O valor da informação é uma função do efeito que ela tem sobre o processo decisório. Se a informação adicional resultar em uma decisão melhor, então ela terá valor" (MORESI, 2000, p. 17).

Para Choo (2003) o valor da informação reside no relacionamento entre a 
informação e quem fará uso dessa informação, processos de busca e uso da informação são atividades sociais humanas "[...] por meio da qual a informação torna-se útil para um indivíduo ou grupo' (CHOO, 2003, p. 118).Comumente "A informação é usada para responder a uma questão, solucionar um problema, tomar uma decisão, negociar uma posição ou dar sentido a uma situação" (CHOO, 2003, p. 119) e o "O conhecimento implícito gera um novo valor quando se torna explícito" (CHOO, 2003, p. 201).

Nas organizações competitivas há uma fetichização da informação como negócio ligada ao processo competitivo, visto que informação gera conhecimento que, consequentemente, gera inovações. Porém, o acúmulo de conhecimento no ambiente organizacional gera informações operacionais potencialmente competitivas para alavancar o processo de produção e a informação como negócio/commodity que, por sua vez, agregada ao processo de produção pode gerar novas inovações e, consequentemente, acúmulo de capital (SANTOS, 2019).

Arrow (1973) afirma que a informação e o conhecimento possuem características e propriedades de não exclusividade e de caráter cumulativo, e que há um paradoxo fundamental na definição de valor da informação - que em um primeiro momento o comprador não sabe que valor atribuir a informação, por não conhecê-la e, em um segundo momento, se já a tiver conhecido e a adquirido sem custo, não se dispõe mais a pagar por ela.

Taylor (1986, tradução nossa) menciona que o valor da informação equivale ao contexto de uso, e a necessidade informacional do indivíduo é que caracteriza este valor, porém depende do contexto e ações em que ela se aplica, visto que a necessidade informacional estabelece processos de mediação e socialização.

Contudo, no âmbito das atividades econômicas é, cada vez mais, reconhecido o papel da informação e das trocas informacionais - a comunicação - como insumos essenciais dos modos de se produzir em sociedade, pois se a informação é como dinheiro, ou seja, é valor, cujo valor precisa de aplicações para gerar mais valor; parado o dinheiro, está morto (JORGE, 2005).

Organizações inteligentes se adaptam criando informações em processos 
contínuos que englobam segundo Davenport e Prusak (1998b) a cadeia de valor da informação determinando: 1) as exigências de informações - identificação do ambiente interno e externo, suas necessidades de informação, fontes e modos de acesso; 2) coleta e aquisição - identificação de necessidades e confiabilidade; 3) classificação e armazenamento - tratamento da informação (atividade humana); 4) compactar e formatar a informação - forma de extração e tratamento para novo suporte e representação; 5) distribuição da informação transferência por meio de canais preestabelecidos; 6) uso da informação tratada com valor agregado pode apoiar a tomada de decisão, reduzir ou aumentar incertezas, pode ser comercializada por meio de produtos ou serviços e agregar outras informações.

As organizações visam reduzir ambiguidades e incertezas visto serem organismos complexos, portanto, "[...] o valor da informação reside no relacionamento que o usuário constrói entre si mesmo e determinada informação. Assim, a informação só é útil quando o usuário the infundir significado, e a mesma informação objetiva poder receber diferentes significados subjetivos de diferentes indivíduos" (CHOO, 2003, p. 70).

A Era da Informação e do Conhecimento evidencia que a informação é uma mercadoria que pode ser comercializada e, sendo assim, é fundamental avaliar seu valor, custo e ganho, bem como fazê-lo em várias perspectivas, pois o excesso ou escassez de informação exige uma reflexão acerca do valor da informação como negócio, visto que "[...] A informação é fabricada por indivíduos a partir de sua experiência passada e de acordo com as exigências de determinada situação na qual a informação deve ser usada [...]" (CHOO, 2003, p. 83).

As organizações devem ter visão ampla do valor econômico, social e cultural da informação e do conhecimento, e devem ter noção do seu valor pragmático, pois são cíclicos, desconhecem limites e se revitalizam com o uso, criando potencialidades estratégicas.

As definições de informação como commodity tem valor diretamente ligados aos processos cognitivos e organizacionais relacionados a socialização da informação entre pessoas, atividades e uso que, por sua natureza imaterial, 
nem sempre tem fácil mensuração (BRAMAN, 1989).

$\mathrm{Na}$ sociedade contemporânea $\mathrm{O}$ modelo econômico voltado a competitividade é real, e tem causado significativas mudanças na estrutura das organizações, visando a tomada de decisão rápida e eficaz. Nesse sentido, a informação e o conhecimento são insumos para desenvolver novos produtos e processos, potencializando o crescimento organizacional, por meio do suporte a tomada de decisão, de maneira a gerar vantagem competitiva. Esses aspectos proporcionam mais flexibilidade para a organização, bem como subsidiam aprender mais rápido, reagir às mudanças do mercado e ter a capacidade de inovar constantemente (SANTOS, 2019).

Ressalta-se que não há consenso quanto a compreensão do que seja 'valor da informação', contudo acredita-se que unidirecionalizar a informação como negócio privilegia características de uma informação conteúdo/ato, além de evidenciar que há o paradoxo de que o valor da informação para quem a adquire somente é conhecido após de fato ter conhecimento desta, em virtude de poder haver dificuldade no processo de apropriação. Bens intelectuais são informações e conhecimentos e, como tais, o valor da informação como negócio deve ser considerado para todos os sujeitos envolvidos no processo.

\section{CONSIDERAÇÕES FINAIS}

A informação como negócio não se estingue no ato de consumo, ao contrário ela aumenta, transforma, reforçando a discussão anteriormente apresentada. Corroborando com Beal (2012) infere-se que a informação pode ser compartilhada e difusa, cujo valor aumenta à medida que são usadas e sofrem associações; a informação é perecível, portanto, a antecipação no que tange a informação é fundamental; o valor da informação aumenta a partir de sua precisão, pois quanto mais precisa, mais útil e valiosa; o valor aumenta quando existem combinações, quanto mais integrada maior a visão sistêmica; quantidade não quer dizer qualidade, o ideal é a informação filtrada, relevante, pois o excesso quando não for bem gerido pode ser prejudicial; a informação se multiplica é autorregenerativa.

A competitividade pressupõe dinamicidade, assim, conhecer o ambiente 
de negócio e se adaptar às mudanças, impõe à necessidade de desenvolver atividades sistematizadas, cujo valor organizacional é inestimável. A competitividade está diretamente relacionada à capacidade de atender continuamente aos desejos e expectativas dos clientes, superando e se antecipando aos concorrentes diretos, bem como desenvolvendo a capacidade de inovar e integrar o que possui de melhor: conhecimento, técnica etc., no intuito de satisfazer as necessidades do cliente e surpreendê-lo.

Sendo assim, reconhecer o valor da informação como negócio com foco na competitividade é pré-requisito para o desenvolvimento organizacional nesse ambiente mutável e complexo, cuja competição se reflete na busca de vantagem, visando estabelecer um diferencial competitivo no mercado.

Evidenciou-se, por meio da análise da literatura, a importância da informação e do conhecimento (formal e informal) e do valor da informação como negócio (valor de uso e troca como objeto e fenômeno que depende de contexto), destacando que a informação tem valor potencial, conforme ressaltam Taylor (1986) e Cooney (1987), a mensagem tem valor potencial, o valor não é intrínseco a mensagem pois este depende de contexto, portanto nunca está saturada, traduz-se em valor em virtude da sua utilidade devendo ser reconhecida como um bem econômico.

O cenário mundial experimenta um acelerado processo de globalização da economia, da cultura etc., competitividade esta que exige a codificação do conhecimento, o transformando em informação passível de ser armazenada/estocada e que propicie sua transferência, se constituindo em negócio no ambiente organizacional.

Acredita-se que ser inteligente no contexto organizacional é usar a informação e o conhecimento de modo eficiente, é tomar decisão visando resolver de maneira satisfatória um problema, é reconhecer os concorrentes, compreender a estratégia do mercado e agir antecipadamente (PORTER, 1991). Nessa perspectiva, defende-se que a informação e o conhecimento contribuem para se obter competitividade, na medida em que geram valor e influenciam o negócio organizacional, uma vez que a competitividade reside em identificar novos mercados ou no reconhecimento do potencial de uma nova tecnologia 
etc., agindo de maneira antecipada, desafiadora e ética.

Propõe-se que pesquisas futuras sejam realizadas sobre a temática valor da informação, seja ele, social, cultural, como negócio, commodity, econômico, monetário etc., conforme apresentada neste ensaio teórico no intuito de potencializar reflexões referentes a temática.

\section{REFERÊNCIAS}

ALMEIDA, C. C.; VARVAKIS, G. Valor e Ciência da Informação: serviços de informação baseados na gestão de operações de serviços. Informação \& Sociedade: Estudos, João Pessoa, v. 15, n. 1, 2005. Disponível em: http://www.periodicos.ufpb.br/ojs/index.php/ies/article/view/52/1522. Acesso em: 12 fev. 2020.

ALMEIDA JUNIOR, O. F. Mediação da informação: um conceito atualizado. In: BORTOLIN, S.; SANTOS NETO, J. A.; SILVA, R. J. Mediação oral da informação e da leitura. Londrina: ABECIN, 2015. p. 9-32.

ARROW, K. J. Higher education as a filter. Journal of Public Economics, [S.I.], v. 2, n. 3, p. 193-216, 1973. DOI: https://doi.org/10.1016/00472727(73)90013-3. Disponível em:

https://www.sciencedirect.com/science/article/abs/pii/0047272773900133. Acesso em: 23 jan. 2020.

BEAL, A. Gestão estratégica da informação: como transformar a informação e a tecnologia da informação em fatores de crescimento e de alto desempenho nas organizações. São Paulo: Atlas, 2012.

BESSON, B.; POSSIN, J. Do serviço de informação à inteligência econômica. Lisboa: Instituto Piaget, 1996.

BOLAÑO, C. Indústria cultural, informação e capitalismo. São Paulo: HICITEC: Polis, 2000.

BRAMAN, S. Defining information: an approach for policymakers.

Telecommunications Policy, [S.I.], v. 13, n. 3, p. 233-242, 1989. Disponível em:

https://pdfs.semanticscholar.org/0269/fe9ff98a484460f33eb05d4c91161e12304 f.pdf. Acesso em: 10 fev. 2020.

BUCKLAND, M. K. Information as thing. Journal of the American Society for Information Science (JASIS), [S.I.], v. 45, n. 5, p. 351-360, 1991. Disponível em: https://skat.inmc.us/rid=1KR7VC4CQ-SLX5RG-5T39/BUCKLAND(1991)informationasthing.pdf. 
CAPURRO, R. Epistemologia e Ciência da Informação. In: ENCONTRO NACIONAL DE PESQUISA EM CIÊNCIA DA INFORMAÇÃO, 5., 2003, Belo Horizonte. Anais [...]. Belo Horizonte: Associação Nacional de Pesquisa e PósGraduação em Ciência da Informação e Biblioteconomia, 2003. Disponível em: http://www.capurro.de/enancib_p.htm. Acesso em: 10 mar. 2020.

CASTELLS, M. O poder da identidade. 5. ed. São Paulo: Paz e Terra, 2001. v. 2 - A era da informação: Economia, sociedade e cultura.

$\mathrm{CHOO}, \mathrm{C}$. W. A organização do conhecimento: como as organizações usam a informação para criar significado, construir conhecimento e tomar decisões. São Paulo: Editora SENAC, 2003. 425p.

CIANCONI, R. Gestão da informação na sociedade do conhecimento. Brasília: SENAI/DN, 1999.

CLEMENTE, A.; SOUZA, A. Considerações de custo e valor da informação. Encontros Bibli: Revista Eletrônica de Biblioteconomia e Documentação, Florianópolis, n. esp., p. 60-74, 2. sem. 2004. Disponível em: https://periodicos.ufsc.br/index.php/eb/article/view/1518-2924.2004v9nesp2p60. Acesso em: 20 jan. 2020.

COONEY, J. P. Qual o real valor da informação? Revista da Escola de Biblioteconomia da UFMG, Belo Horizonte, v. 20, n. 2, p. 176-190, jul./dez. 1991. Disponível em: http://hdl.handle.net/20.500.11959/brapci/75463.

DAVENPORT, T.; PRUSAK, L. Conhecimento empresarial: como organizações gerenciam o seu capital intelectual. Rio de Janeiro: Campus, 1998a.

DAVENPORT, T.; PRUSAK, L. Ecologia da informação: porque só a tecnologia não basta para o sucesso na era da informação. São Paulo: Futura, 1998b. 316p.

HERSCOVICl, A. Trabalho, capital intangível e historicidade do valor: uma tentativa de definição do capitalismo imaterial. In: MARQUES, R. M.; RASLAN, F.; MELO, F.; PINHEIRO, M. M. K. (org.). A informação e o conhecimento sob as lentes do marxismo. Rio de Janeiro: Garamond, 2014. p. 77-98

ILHARCO, F. Filosofia da informação: uma introdução a informação como fundação da ação, da comunicação e da decisão. Lisboa: Universidade Católica Editora, 2003.

JORGE, V. O. Informação, comunicação, investigação, interdisciplinaridade e mediação na sociedade actual: algumas notas prévias a uma antropologia de certos comportamentos contemporâneos. Revista da Faculdade de Letras Ciências e Técnicas do Património, Porto, v. 4, n. 1, p. 43-51, 2005. Disponível em: http://ler.letras.up.pt/uploads/ficheiros/4935.pdf. Acesso em: 14 fev. 2020. 
KIRK, J. Information in organizations: directions for information management. InformationResearch, Austrália, v. 4, n. 3, Feb. 1999. Disponível em: http://www.informationr.net/ir/4-3/paper57.html. Acesso em: 3 fev. 2020.

LOPES, R. S. Informação, conhecimento e valor. São Paulo: Radical Livros, 2008.

MARX, K. O capital. São Paulo: Abril Cultural, 1984. v. 1; tomo 2.

MORESI, E. A. D. Delineando o valor do sistema de informação de uma organização. Ciência da Informação, Brasília, v. 29, n. 1, p. 14-29, jan./abr. 2000. Disponível em: http://www.scielo.br/pdf/ci/v29n1/v29n1a2.pdf. Acesso em: 20 mar. 2020.

MORIN, E. O método 3: o conhecimento do conhecimento. Porto Alegre: Sulina/Meridional, 1999. 288p.

NONAKA, I.; TAKEUCHI, H. Criação do conhecimento na empresa: como as empresas japonesas geram a dinâmica da inovação. 5. ed. Rio de Janeiro: Campus, 1997. 358p.

PORTER, M. E. A vantagem competitiva das nações. Rio de Janeiro: Campus, 1991. 897p.

REZENDE, J. F.; PEREIRA, R. D.; OLIVEIRA, D. A. Plataformas para gestão do conhecimento: estudo de caso sobre a ativação do valor de excedentes cognitivos por meio do desenvolvimento de um contexto capacitante virtual.

Perspectivas em Gestão e Conhecimento, João Pessoa, v. 6, n. 1, p. 72-88, jan./jul. 2016. Disponível em:

http://www.periodicos.ufpb.br/ojs/index.php/pgc/article/view/26312/15474.

Acesso em: 20 ago. 2020.

SANTOS, Juliana Cardoso dos. Memória organizacional: o valor da informação como negócio/commodity. Orientadora: Marta Lígia Pomim Valentim. 2019. 223f. Tese (Doutorado em Ciência da Informação) - Faculdade de Filosofia e Ciências, Universidade Estadual Paulista "Júlio de Mesquita Filho", Marília, 2019. Disponível em:

https://repositorio.unesp.br/bitstream/handle/11449/183566/santos_jc_dr_mar.p df? sequence=3\&isAllowed=y. Acesso em: 20 fev. 2020.

SANTOS, J. C.; COSTA, A. R.; FERREIRA, C. F.; COELI, C. B. N.; ROCHA, F. R. M.; REIS, J. L.; MENDES, J. S. O valor da informação: em foco o processo de inteligência competitiva. In: SEMINÁRIO EM CIÊNCIA DA INFORMAÇÃO, 7., 2017, Londrina. Anais [...]. Londrina: UEL, 2017. Disponível em: http://www.uel.br/eventos/cinf/index.php/secin2017/secin2107/paper/viewFile/4 10/297. Acesso em: 13 mar. 2020. 
SETZER, V. W. Dado, informação, conhecimento e competência. DataGramaZero, Rio de Janeiro, n. 0, dez. 1999. Disponível em: https://brapci.inf.br/index.php/res/v/7327

SEVERINO, A. J. Metodologia do trabalho científico. 23. ed. São Paulo: Cortez, 2007. 304p.

SHETH, J.; MITTAL, B.; NEWMAN, B. Comportamento do cliente: indo além do comportamento do consumidor. São Paulo: Atlas, 2001.

TARAPANOFF, K. (org.). Inteligência, informação e conhecimento. Brasília: IBICT; UNESCO, 2006.

TARAPANOFF, K.; ARAÚJO JR., R. H.; CORMIER, P. M. J. Sociedade da informação e inteligência em unidades de informação. Ciência da Informação, Brasília, v. 29, n. 3, p. 91-100, set./dez. 2000. Disponível em: https://www.scielo.br/pdf/ci/v29n3/a09v29n3. Acesso em: 11 fev. 2020.

TAYLOR, R. S. Value-added processes in information system. Norwood: Ablex, 1986, 257p.

TRIVIÑOS, A. N. S. Introdução à pesquisa em ciências sociais - a pesquisa qualitativa em educação: o positivismo, a fenomenologia, o marxismo. São Paulo: Atlas, 1990.175p.

VALENTIM, M. L. P. Informação estratégica: insumo para tomada de decisão. Palavra-Chave, São Paulo, n. 7, p. 5-6, 1994.

VALENTIM, M. L. P. Processo de inteligência competitiva organizacional. In: VALENTIM, M. L. P. (org.). Informação, conhecimento e inteligência organizacional. Marília: FUNDEPE Editora, 2006. 281p.; p. 9-24.

VALENTIM, M. L. P.; GELINSKI, J. V. V. Gestão do conhecimento como parte do processo de inteligência competitiva organizacional. Informação \& Sociedade: Estudos, João Pessoa, v. 15, n. 2, p. 41-59, jul./dez. 2005. Disponível em: https://brapci.inf.br/index.php/res/v/92962. Acesso em: 11 fev. 2020.

VALENTIM, M. L. P. Informação e conhecimento em organizações complexas. In: VALENTIM, M. L. P. (org.). Gestão da informação e do conhecimento no âmbito da Ciência da Informação. São Paulo: Polis: Cultura Acadêmica, 2008, p. 11-26; 268p.

\title{
INFORMATION, KNOWLEDGE AND INFORMATION VALUE
}

\author{
ABSTRACT \\ Introduction: Information and knowledge in organizational environments are essential
}


resources that have strategic value and is interrelated with productivity and organizational competitiveness. Objective: To show through the literature, the importance of information and knowledge for the attribution of value to the organizational business. Methodology: Regarding methodological procedures, this theoretical essay is of a qualitative nature, typologically descriptive and exploratory, aiming to show through the literature, the importance of information and knowledge for the generation of value to the organization's business. Results: As a result, it was identified that there is still no consensus in the area of Information Science - and there is no need for it, on the value of information as a business. Conclusions: It is considered that the findings of this research contribute to enrich the theoretical framework of the scientific field of Information Science, considering that it is a theme that is a trend, but also a necessity in organizational studies.

Descriptors: Information. Knowledge. Information Value.

\title{
INFORMACIÓN, CONOCIMIENTO Y VALOR DE LA INFORMACIÓN
}

\begin{abstract}
RESUMEN
Introducción: la información y el conocimiento en entornos organizacionales son recursos esenciales que tienen un valor estratégico y están interrelacionados con la productividad y la competitividad organizacional. Objetivo: Mostrar a través de la literatura, la importancia de la información y el conocimiento para la atribución de valor al negocio organizacional. Metodología: En cuanto a los procedimientos metodológicos, este ensayo teórico es de naturaleza cualitativa, tipológicamente descriptivo y exploratorio, con el objetivo de mostrar a través de literatura, la importancia de la información y el conocimiento para generar valor para el negocio de la organización. Resultados: Como resultado, se identificó que todavía no hay consenso en el área de Ciencias de la Información, y no es necesario que exista, sobre el valor de la información como negocio. Conclusiones: se considera que los resultados de esta investigación contribuyen a enriquecer el marco teórico del campo científico de la Ciencia de la Información, considerando que es un tema que es una tendencia, pero también una necesidad en los estudios organizacionales.
\end{abstract}

Descriptores: Información. Conocimiento. Valor de la Información.

Recebido em: 27.04.2020

Aceito em: 20.11.2020 